\title{
Complementarity of Sentinel-1 and Sentinel-2 Data for Mapping Agricultural Areas in Senegal
}

\author{
Gayane Faye ${ }^{1}$, Fama Mbengue ${ }^{1}$, Lacina Coulibaly ${ }^{2}$, Mamadou Adama Sarr ${ }^{3,4}$, Modou Mbaye ${ }^{1}$, \\ Amath Tall1,5, Dome Tine1, Omar Marigo', Mouhamadou Moustapha Mbacke Ndour ${ }^{6}$
}

\author{
${ }^{1}$ Laboratoire de Télédétection Appliquée, Institut des Sciences de la Terre, Cheikh Anta DIOP University of Dakar \\ (LTA/IST/UCAD), Dakar, Senegal \\ ${ }^{2}$ Laboratoire de Géomatique Environnementale, École de Foresterie, Université de Moncton, Nouveau-Brunswick, Canada \\ ${ }^{3}$ Centre de Suivi Ecologique (CSE) of Dakar, Dakar, Senegal \\ ${ }^{4}$ Laboratoire d'Études et de Recherche en Statistique et Développement, UFR de Sciences Appliquées et de Technologie, \\ Département de Mathématiques Appliquées, Université Gaston BERGER of Saint-Louis, Dakar, Senegal \\ ${ }^{5}$ Ecole Nationale Supérieure d'Agriculture (ENSA), Thies University, Thies, Senegal \\ ${ }^{6}$ UFR Science de l'Ingenieur, Thies University, Thies, Senegal \\ Email: *gayane.faye@gmail.com
}

How to cite this paper: Faye, G., Mbengue, F., Coulibaly, L., Sarr, M.A., Mbaye, M., Tall, A., Tine, D., Marigo, O. and Ndour, M.M.M. (2020) Complementarity of Sentinel-1 and Sentinel-2 Data for Mapping Agricultural Areas in Senegal. Advances in Remote Sensing, 9, 101-115. https://doi.org/10.4236/ars.2020.93006

Received: November 17, 2020

Accepted: September 27, 2020

Published: September 30, 2020

Copyright $\odot 2020$ by author(s) and Scientific Research Publishing Inc. This work is licensed under the Creative Commons Attribution International License (CC BY 4.0).

http://creativecommons.org/licenses/by/4.0/

\begin{abstract}
The small size of agricultural plots is the main difficulty for crops mapping with remote sensing data in the Sahelian region of Africa. The study aims to combine Sentinel-1 (radar) and Sentinel-2 (Optic) data to discriminate millet, maize and peanut crops. Training plots were used in order to analyse temporal variation of the three crops' signals. The NDVI (Normalized Difference Vegetation Index) was able to differentiate crops only at the end of the rainy season (October). The optical data as well as the radar ones could not easily discriminate the three crops during the growing season, because in that period vegetation cover is low, and soil contribution to the signals (due to roughness and moisture) was more important than that of real vegetation. However, the ratio of $\mathrm{VH} / \mathrm{VV}$ ( $\mathrm{VH}$ : incident signal in vertical polarization and reflected signal in horizontal polarization; VV: incident signal in vertical polarization and reflected signal in horizontal polarization) gave a difference between millet and the two other crops at the beginning cultural season (July 11). Difference appears from the second third of September when the harvest of cereals crops (millet and maize) began. From middle of October, the peanut signal dropped sharply thus facilitating the differentiation of peanut from the two other crops. This analysis led to the identification of data that have could be used to discriminate these crops (useful data). Classification of the combined useful data gave an overall high accuracy of $82 \%$, with $96 \%, 61 \%$ and $65 \%$ for peanut, maize and millet, respectively. The non-agricultural areas (water, natural vegetation, habit, bare soil) were well classified with an accuracy greater than $90 \%$.
\end{abstract}




\section{Keywords}

Agricultural Areas, Remote Sensing, Sentinel-1, Sentinel-2, Senegal

\section{Introduction}

Senegal is a country where agriculture is mainly rainfed (with only $5 \%$ of the land being irrigated [1], making agricultural production subject to climatic hazards. In recent years, several public and private actions have been initiated to improve agricultural productivity, but the agricultural system is especially vulnerable to climate change. The lack of reliable and recent data is a barrier to good management of the sector's challenges. In this context, remote sensing can provide considerable benefits to improve the accuracy of agricultural data and statistics.

In recent years, many studies have shown the value of using remote sensing for agricultural monitoring in divers situations [2]-[9]. Satellite remote sensing techniques for monitoring and mapping crops are mainly based on the approach of spectral treatment using thematic indices such as NDVI (Standardized Difference Vegetation Index) and LAI (Leaf Area Index) [10] [11] [12]. The main limitation of this approach has the low discrimination in the context of very heterogeneous micro-plots of culture [13]. In Senegal, high crop diversity and small parcel size are important challenges to crop mapping at the plot scale using Earth observation data.

In the recent years, the availability of time series of optical and radar images time series with high spatial and temporal resolutions has brought particular interest for agricultural mapping at the plot scale. This is especially true since the different crops to be discriminated do not have the same phenological cycles [14] [15] [16].

With the high sensitivity of certain wavelengths to chlorophyl activity and also to plant characteristics (density, biological cycle, etc.), optics is an effective means of monitoring vegetation [17] [18] [19] [20] [21]. Sentinel-2 data, with 13 spectral bands provides a good solution for distinguishing between different crops. However, the sensitivity of optical sensors to atmospheric conditions is often a limitation for monitoring vegetation during the rainy season due to cloud cover.

Conversely, radar data are not disturbed by atmospheric conditions but their sensitivity to different surface parameters (soil roughness, soil moisture and vegetation) limit their efficiency in the monitoring and mapping of herbaceous vegetation [22]. However, analysing the temporal profile of these data under different polarizations can provide important information to discriminate types of crops, especially because of differences in phenological cycles plant shapes and sizes during the various stages of the growing season [23].

This work aims to test the complementarity of optical and radar images, on 
the one hand, and the temporal evolution of these two types of signals during the agricultural season on the other hand. By combining time series for Sentinel-2 (optical) and Sentinel-1 (C-band radar), we expect to be able to discriminate between different crops at the plot scale, enabling better monitoring of agricultural areas in the Senegalese context.

\section{Materials and Methods}

\subsection{Study Area}

The study area, about $400 \mathrm{~km}^{2}$, is in the department of Nioro du Rip (Figure 1). It is located between latitudes $13.64^{\circ}$ and $13.82^{\circ}$ north, and longitudes $-15.74^{\circ}$ and $-15.92^{\circ}$ west and belongs to the groundnut production basin, which is the most important agricultural region of Senegal.

The climate is of the Sahelian type, with two seasons: a dry season (mid-October to mid-June) and a rainy one (mid-June to mid-October) marked by a strong interannual variability. Each year, between $900-1100 \mathrm{~mm}$ is recorded during the three months of the rainy season, causing strong hydric erosion often causing extensive gullying.

Demographic pressure has strongly modified the agricultural system, notably with deforestation and the abandonment of fallow cropping cycles [24].

The agricultural system is shared between cash crops dominated by peanuts and cereal crops mainly composed of millet and maize grown on small parcels of about 2 hectares.

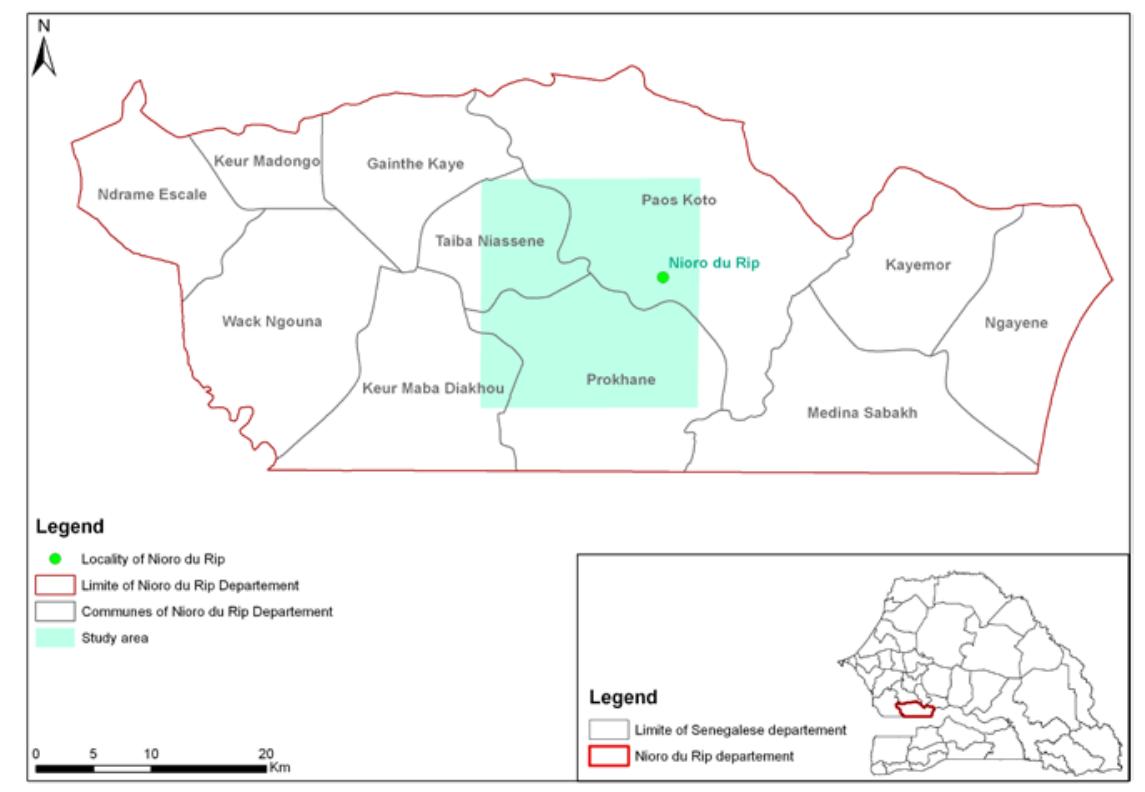

Figure 1. Location of study area.

\subsection{Field Data}

The field data consisted of 168 control plots (59 of peanut, 55 of maize and 54 of millet), serving as a training and validation plots (Figure 2). Field missions were 


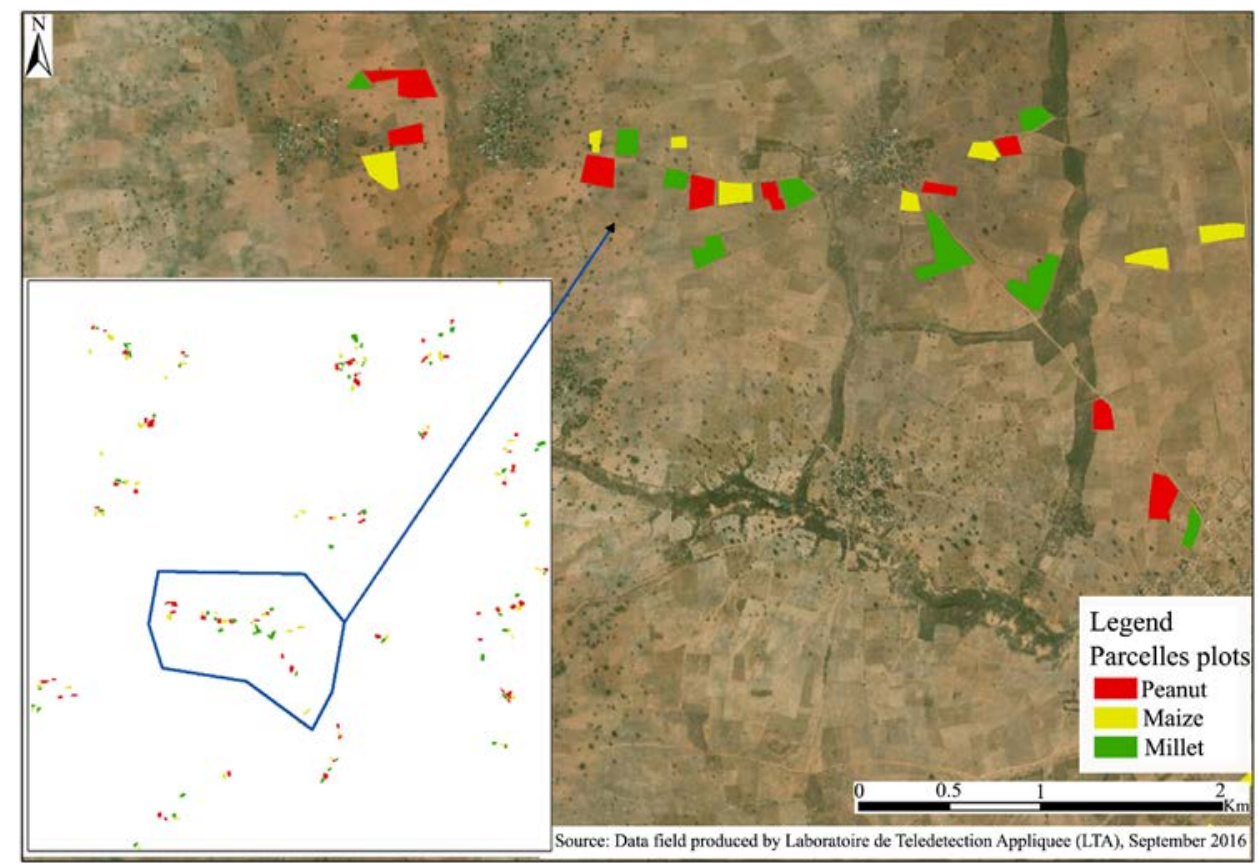

Figure 2. Spatial repartition of control plots.

carried out during the crop growth period to delimit control plots contours (digitization of contours) with GPS (Global Position System). The choice of plots was based on several criteria including the spatial representativeness of each crop, the level of growth and density. This to have a good spatial representativeness of each type of culture. In order to avoid edge effects and eliminate mixed pixels between contiguous plots of different crops, plots borders were adjusted from Google Earth.

\subsection{Satellite Image Data}

Two datasets from multiple dates during the 2016 rainy season (June to October) were used for Sentinel-2A (Optical) and Sentinel-1A (Radar), as shown in Table 1.

Sentinel-2A multispectral images are available on the ESA (European Space Agency) website (https://sentinel.esa.int/web/sentinel). These are level-1C products, with resolutions from 10 meters (visible + near-infrared bands) to 60 meters, organized in $100 \mathrm{~km} \times 100 \mathrm{~km}$ ortho-rectified tiles in UTM WGS84 projections. Data from the T28PDA tile, which fully covers the study area were used. Although the satellite imaging periodicity is 10 days, only three images had less than $10 \%$ cloud cover rate: 0 ! And 18 of August and 07 of October, with $0.22 \%, 5.8 \%$ and $0 \%$ of cloud cover, respectively.

Sentinel-1 data, are available on the https://scihub.copernicus.eu/dhub website and on the Sentinel product exploitation platform (PEPS) http://scihub//peps.cnes.fr. Sentinel-1 is a C-band Synthetic Aperture Radar (SAR) sensor that provides images at 10 meters of spatial resolution in two $\mathrm{VV}$ and $\mathrm{VH}$ polarizations mode. As radar data are not affected by cloud cover, a total of 14 images were analysed. 
Table 1. Satellite data acquisition date.

\begin{tabular}{ccccccccccccccc}
\hline Month & June & July & \multicolumn{2}{c}{ August } & September & October & \multicolumn{2}{c}{ November } & December \\
\hline Sentinel-2A & & & & 08 & 18 & & & 07 & & & & \\
Sentinel-1A & 29 & 11 & 23 & 16 & 28 & 09 & 21 & 03 & 15 & 27 & 08 & 20 & 14 & 26 \\
\hline
\end{tabular}

\section{Methods}

The work was done in four steps (Figure 3).

The first step in the work was to correct the satellite data. Downloaded optical data (Level 1C) were corrected using ESA's Sen2Cor algorithm to suppress atmospheric effects and convert numerical values to reflectance (Level-2A). Radar data were corrected for geometric distortions (geocoding, georeferencing), and filtered to reduce speckle. The data were then normalized (radiometric calibration) in order to be able to perform the multi-temporal analyses. This required transforming the backscattered signal (Digital Number) into a dimensionless quantity called sigma backscattering coefficient $\left(\sigma^{\circ}\right.$ in $\mathrm{dB}$ ) proportional to the ratio of power received and power transmitted at the antenna [25].

Secondly pixel values were extracted for control plots for all the images (optical and radar), with plot boundaries being adjusted to avoid contiguous pixels.

In the third step, data was analysed to explore their ability to differentiate between the three types of crops. For optical data, the spectral signature of the three cultures for the three dates (08 and 18 of August, 07 of October) was carried out to determine the bands and the periods for optimal discrimination. Pair-wise comparison of individual parcels across the three dates where used to determine which date would provide optimal discrimination for subsequent NDVI analysis. The dispersion of radar data was evaluated by comparing the mean and median values of the backscattering coefficients of each crop to see the influence of the extreme values. This is usually caused by the sensitivity of the radar signal to humidity and soil roughness, especially at the beginning of the growing season when the plant cover is low [22] [26]. Subsequently, the temporal profiles of the signals of the three cultures following under two polarizations ( $\mathrm{VV}$ and $\mathrm{VH}$ ) were analysed and compared in order to look for differences in backscattering between the cultures during their phenological cycle. These analyses showed that the relationship between the two polarizations can improve the differentiation of cultures. An index called $\mathrm{I}_{\mathrm{G}}\left(\mathrm{I}_{\mathrm{G}}=2 * \operatorname{Exp}(\mathrm{VH} / \mathrm{VV})\right.$ was calculated for each date and its temporal profile analysed. the purpose of this index is to highlight the spectral differences of crops that the polarizations taken individually do not able to show. Finally, the differences between the signals of the cultures taken two by two were analysed to identify dates exhibiting significant differences (more than $5 \mathrm{~dB}$ ). This allowed the selection of the most discriminating images.

Finally, the most discriminating optical and radar data were combined to map different crops. Two thirds of the control plots were randomly selected to provide a training base. Segmentation was then used to delineate the contours of the 


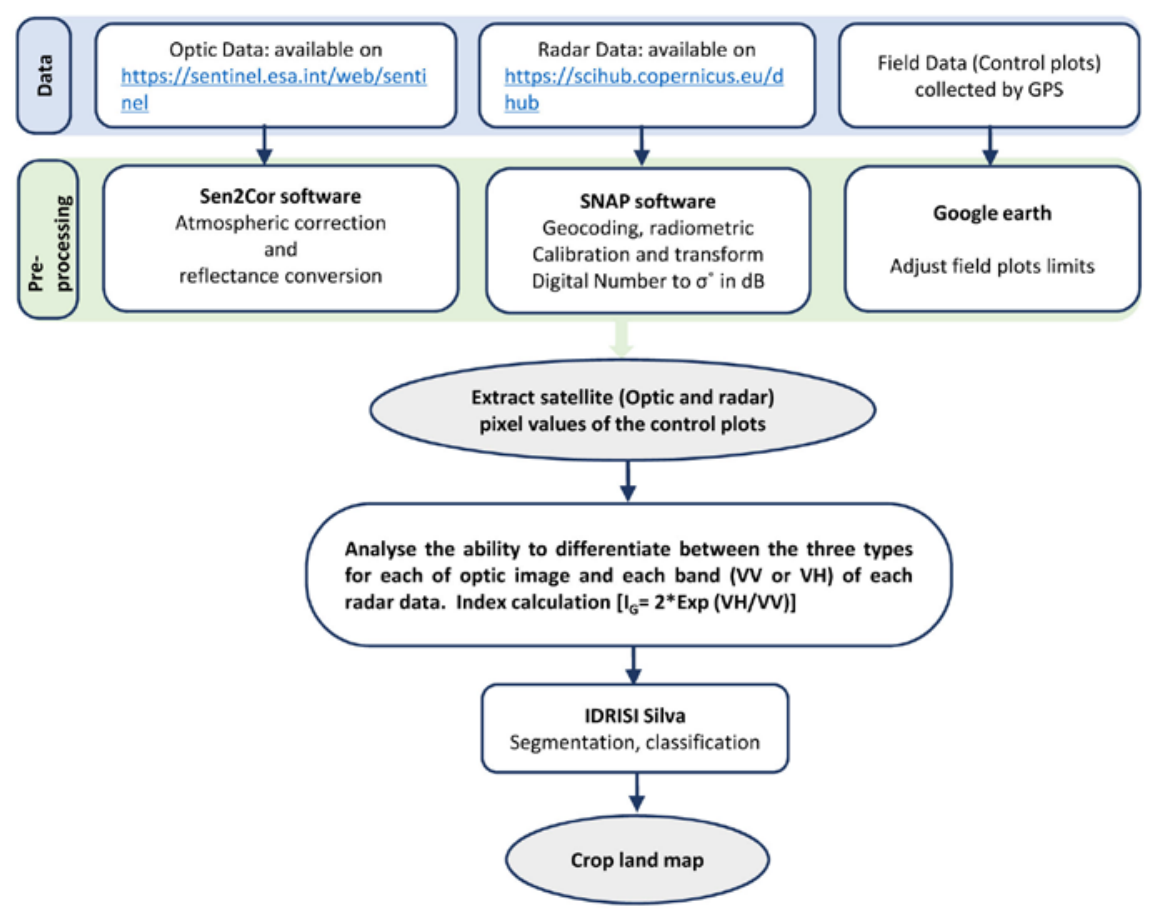

Figure 3. Flow chart of the method.

homogeneous sets grouping pixels which had similar criteria and form them into subsets, homogeneous regions or segments [27]. This was undertaken with Idrisi Silva software which enables several images with different characteristics (spatial resolution, sensors, etc) to be combined. The combination of segmentation and classification results was used to produce yielded a crop map which accuracy was then tested using the one third of the control plots.

\section{Results and Discussions}

\subsection{Optical Data}

The analysis of the spectral signature of the three crops for the three dates showed a strong confusion in the visible, especially during the growth phase (August). However, towards the end of the cropping season (October images), differences between peanut and cereal crops (millet and maize), were noted especially in the near infrared (PRI, $730 \mathrm{~nm}$ ) as shown in Figure 4. There were also small differences in the red band $(665 \mathrm{~nm})$. This shows that the NDVI could differentiate the three crops during this period (October). For this reason, investigations were then limited to NDVI in the rest of the optical data analysis.

NDVI values for August were strongly correlated (Figure 5(a)) but overall maize values were low (less than 0.18 on August $8^{\text {th }}$ and 0.3 on August $18^{\text {th }}$ ). In October, the NDVI of the peanut remained generally higher than that of millet (Figure 5(b) and Figure 5(c)). It can be deduced that August was not suitable to discriminate crops. The NDVIs values of October, showed a good discrimination of the three crops, in particular between peanut and millet. Further analysis was based solely on the image of October $7^{\text {th }}$. 

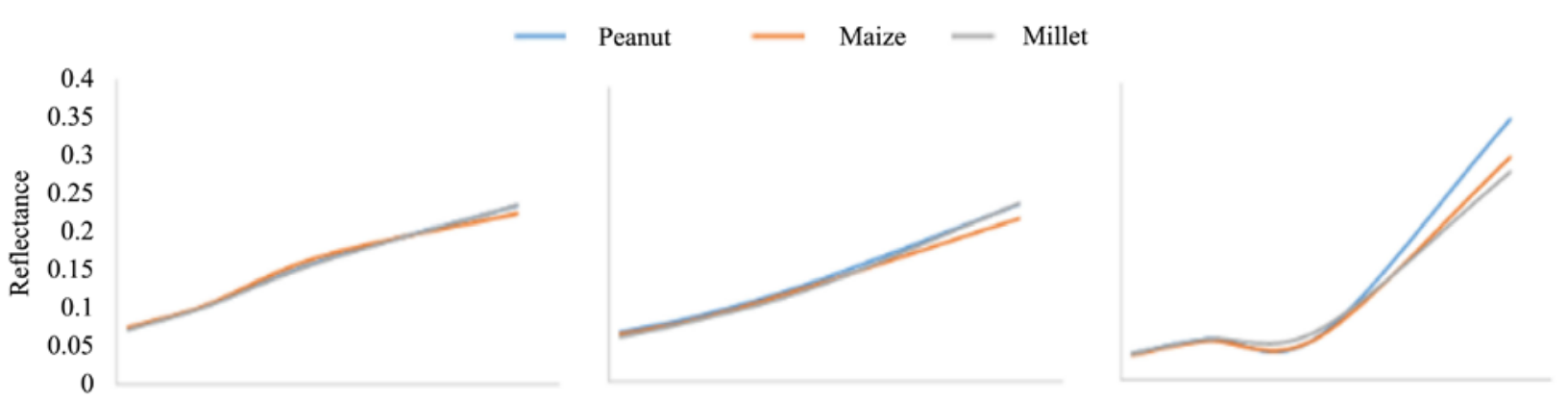

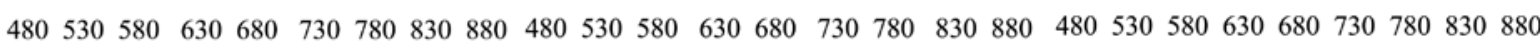

Wavelength (nm)

(a)
Wavelength (nm)

(b)
Wavelength (nm)

(c)

Figure 4. Spectral signature of the three crops in: (a) August 08; (b) August 18 and (c) October 07, 2016.

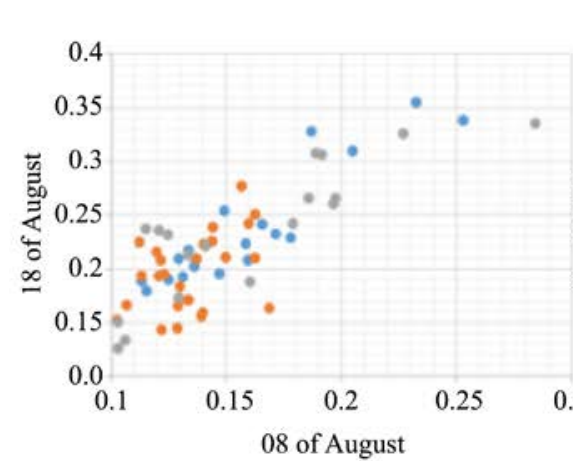

(a)

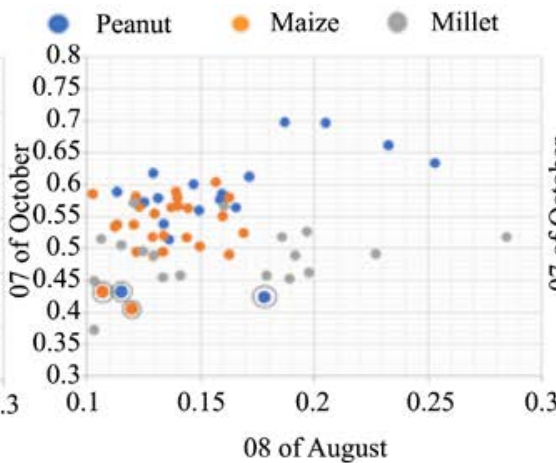

(b)

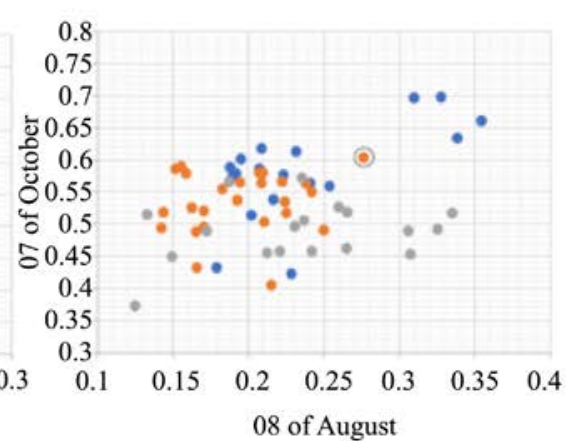

(c)

Figure 5. Comparison of the NDVIs of crops of the three dates.

\subsection{Radar Data}

The radar signals were sensitive to seasonal variability for all three crops. This is consistent with other research obtained for C-band radar over the entire Sahelian band [28] [29]. On the other hand, the VV polarization signal remained higher than that in $\mathrm{VH}$. This is because the penetration ability of a wave through a plant layer depends on the geometry, the orientation, the size, the density as well as and the dielectric constant of the elementary diffusers constituting them [30].

The signals for each of the three crops were similar during the growth phase (Figure 6(a)). This situation is explained by the fact that during this period, the contribution of soil (roughness and humidity) was often greater than that of vegetation because of the low vegetation cover [22]. It was therefore difficult to discriminate crops during the first part of the rainy season. However, the $\mathrm{I}_{\mathrm{G}}$ index showed a difference between millet and the two other crops at the $192^{\text {nd }}$ and $204^{\text {th }}$ day of year corresponding to July 11 and July 23 . This difference could be the result of cultural practices that differ from one crop to the other. Millet is sown before the onset of rains unlike maize and peanut where the crop requires deep plowing. As a result, the roughness of the soil is very different between 
millet fields and those of maize and peanut. This explains the fact that the $\mathrm{VH} / \mathrm{VV}$ ratio amplified by the exponential function differentiated millet from the other two crops.

During the period of maturity and harvest, significant differences were observed between peanut and cereal crops (Figure 6(a)). This situation is explained by the fact that harvesting the peanut crop leaves a bare soil, unlike the harvest of the two cereal crops (millet and maize) which only removes the ears and leaves the stalks in place to slowly dry and die. Thus, peanut signal drops sharply after the harvest, when millet and maize are slowly declining.

Pairwise comparison of the signals for the different crops showed that the difference between the peanut signal and the two cereals can reach $2 \mathrm{~dB}$ in VV and up to $5 \mathrm{~dB}$ in $\mathrm{VH}$ towards the end of the rainy season $\left(326^{\text {th }}\right.$ day of year corresponding to November $20^{\text {th }}$ ). This shows that it is possible to discriminate peanut from cereal crops in that period. However, the difference between the millet and maize signal was very small and rarely exceeded $1 \mathrm{~dB}$ (Figure 7).

In conclusion, the images of July 11 (193 ${ }^{\text {rd }}$ Julian days) and November 20 (324 $4^{\text {th }}$ Julian days) were the most discriminating. In fact, the $\mathrm{I}_{\mathrm{G}}$ index of July 11 differentiated the millet from the two other crops and the image of November $20^{\text {th }}$ discriminated peanut from millet and maize in $\mathrm{VV}$ and $\mathrm{VH}$ polarization.

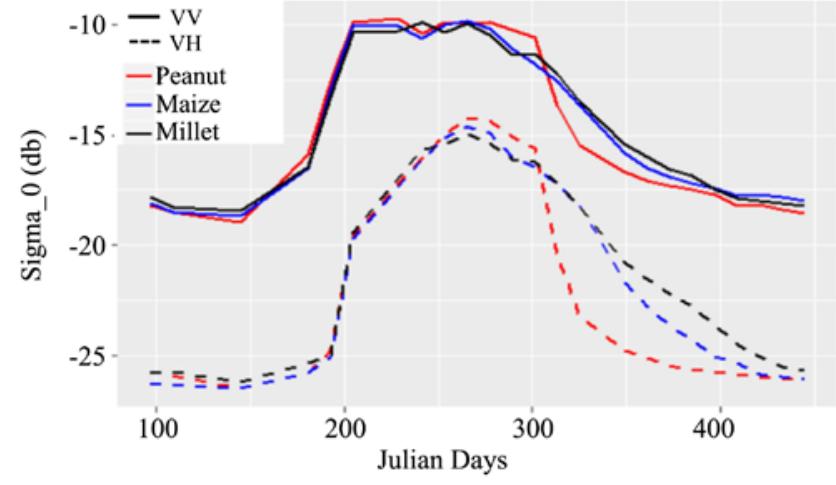

(a)

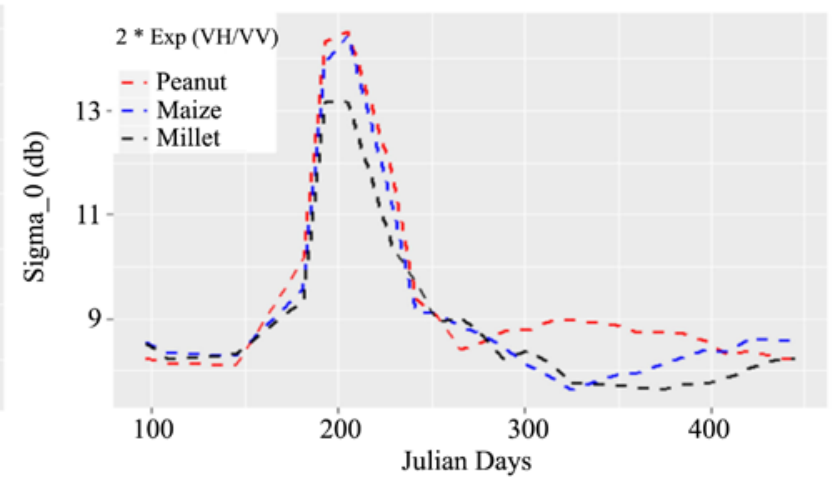

(b)

Figure 6. Temporal evolution of three crops signal (a) in VV and VH polarisation (b) $\mathrm{I}_{\mathrm{G}}$ index $\left(2{ }^{*} \operatorname{Exp}(\mathrm{VH} / \mathrm{VV})\right)$.

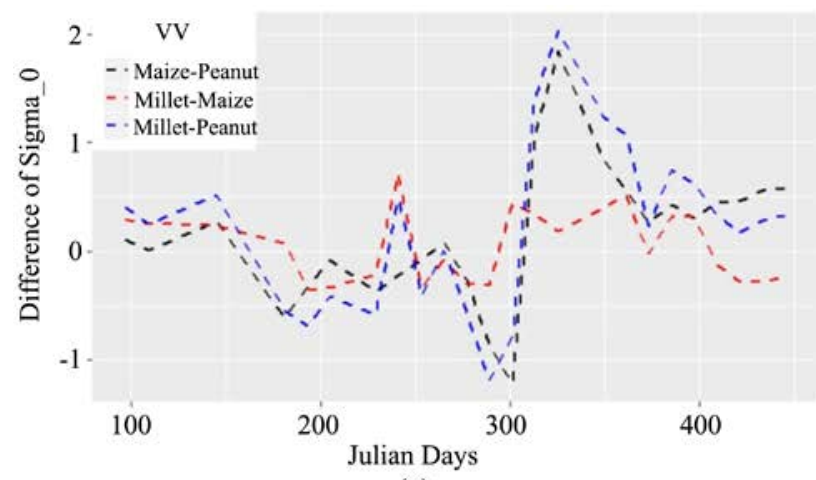

(a)

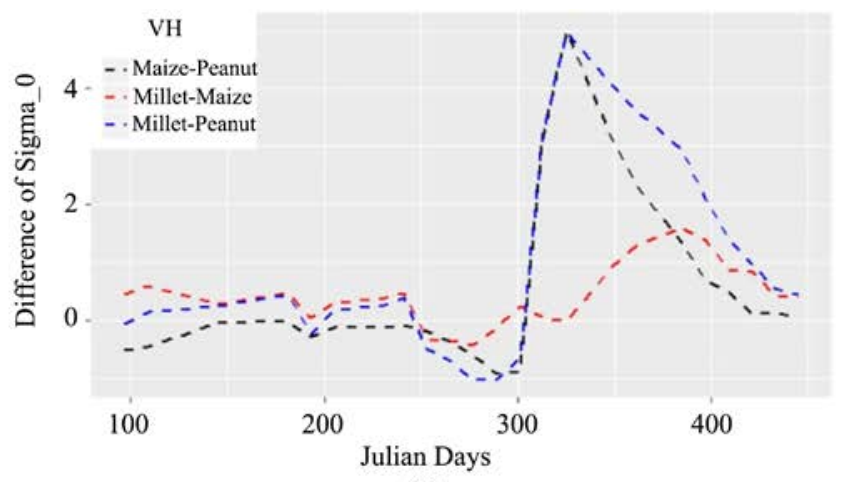

(b)

Figure 7. Temporal evolution of the differences between crops signal taken in pairs in (a) VV polarisation and (b) VH polarization. 


\subsection{Combining of Optical and Radar Data}

The false color compositions between the different images (NDVI of October $7^{\text {th }}$, VV and VH polarization of July 11 and November 20) make it possible to highlight differences in land cover (Figure 8):

- NDVI combined with VH polarization (July $11^{\text {th }}$ and November $20^{\text {th }}$ Figure $8(a)$ ) or with VV (July $11^{\text {th }}$ and November $20^{\text {th }}$ Figure 8(b)) highlighted habitations (yellow) and water (black);

- The combination of the NDVI with the VV and VH of July 11 (Figure 8(c)) brought out the natural vegetation zones (green);

- The NDVI with VV and VH of November 20 (Figure 8(d)) showed differences between crops (black for peanut, green for millet and yellow maize);

- The image of July $11^{\text {th }}$ (VV and VH polarization) with the VH of November $20^{\text {th }}$ (Figure 8(e)) or with VV of November $20^{\text {th }}$ (Figure 8(f)) highlighted the heterogeneity of agricultural areas, although there is significant noise was observed;

- The image of November $20^{\text {th }}(\mathrm{VV}$ and $\mathrm{VH})$ combined with VH of July $11^{\text {th }}$ (Figure $8(\mathrm{~g})$ ) or with the $\mathrm{VV}$ of July $11^{\text {th }}$ (Figure $8(\mathrm{~h})$ ) showed differences between crops.

Combined optical and radar data combination reduced the noise. This shows once again the importance of associating these two types of data for crop mapping. The radar showed a sensitivity of the different crops at different dates but with a background noise on the images while the optical image (NDVI October 07) is able to reduce noise and facilitated the detection of contours.

The segmentation performed from the five combined images (NDVI of October $7^{\text {th }}, \mathrm{VV}$ and $\mathrm{VH}$ of July $11^{\text {th }}$ and $\mathrm{VV}$ and $\mathrm{VH}$ of November $20^{\text {th }}$ ) allowed the distribution the pixels in homogeneous segments. The segmentation results were merged with the result of the supervised classification to smooth and refine the result (Figure 9). Finally, to assess the validity of the result, a confusion matrix was calculated using $1 / 3$ of the remaining data (Table 2). The overall error of the classification was $14 \%$ with a Kappa coefficient of 0.83 . This error is mainly due to the strong confusion between the two cereals where $32 \%$ of the maize fields were classified as millet and $30 \%$ of millet fields were considered as maize. Thus, maize presented a global classification error of $38 \%$ and millet has a $34 \%$ error, while the error in classifying peanut only $7 \%$. Non-agricultural areas were well identified with much lower errors for water (0.5\%), natural vegetation (4.6\%), habitation (2.4\%) and bare soil (6.2\%).

Optical signals for the three crops were poorly distinguished during the growing season (August). This is partly because during this period the coverage rates are almost identical for all crops [23] and so, all fields reflected in almost the same way making the differentiation of crops difficult. Only the infrared wavelength detected a slight difference for maize or the reflectance remained lower than that of millet and peanut. In October, the peanut NDVI stood out clearly from that of millet with a sort of barrier around 0.55 . This is explained by 


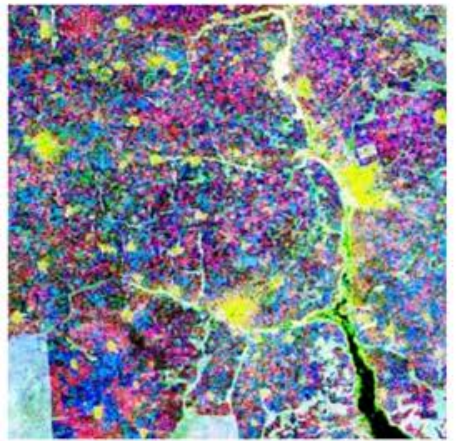

NDVI ( 07 October), VH (11 July \& 20 November)

(a)

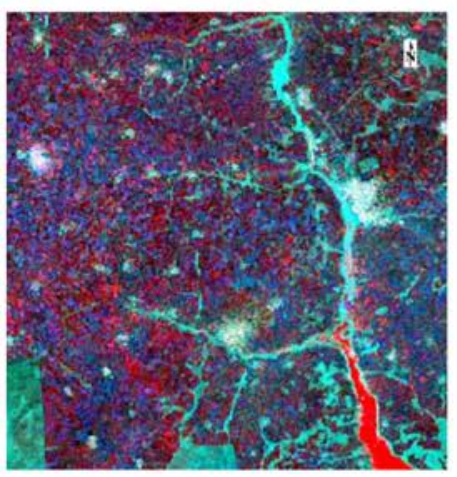

NDVI ( 07 October), VH et VV (11 July)

(c)

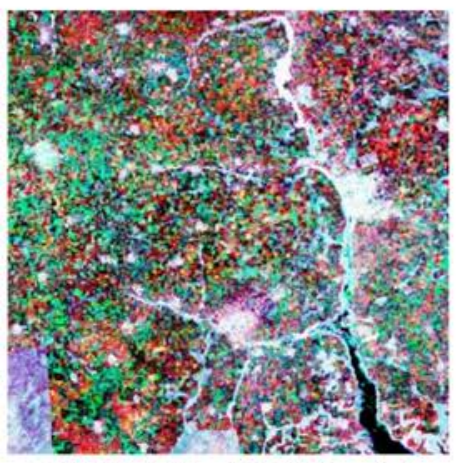

VH \& VV (11 July) and VH (20 November)

(e)

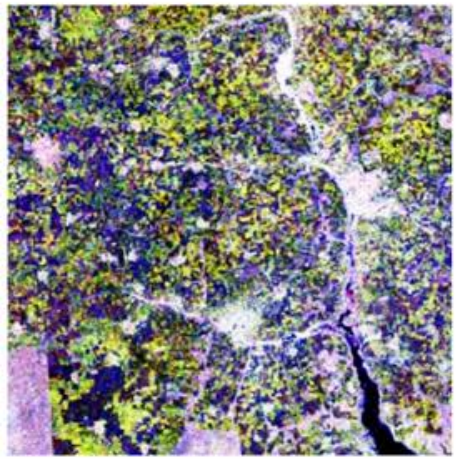

VH (11 July) and VH \& VV (20 November)

(g)

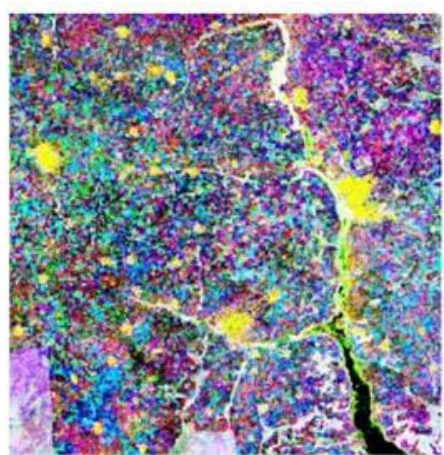

NDVI ( 07 October), VV (11 July et 20 November)

(b)

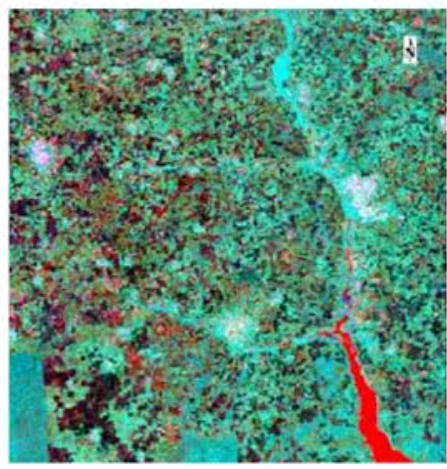

NDVI (07 October), VH \& VV (20 November)

(d)

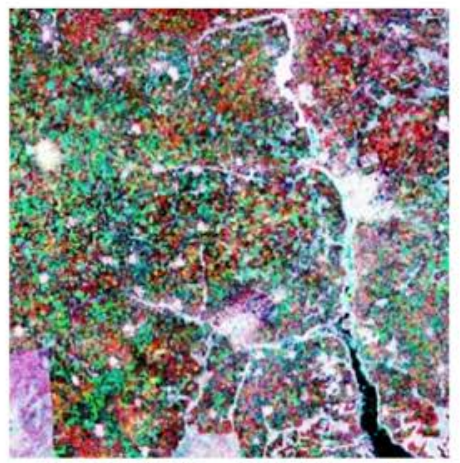

VH \& VV (11 July) and VV (20 November)

(f)

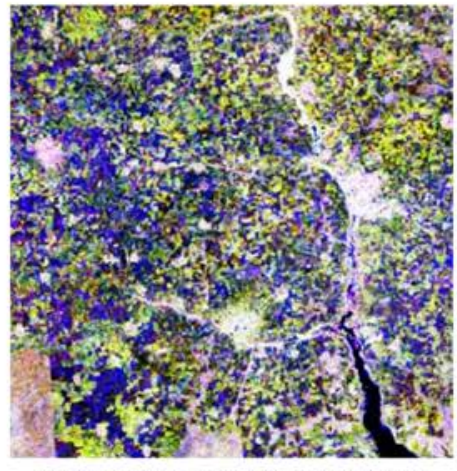

VV (11 July) and VH \& VV (20 November)

(h)

Figure 8. Color composite images created by combining optical and radar data. 


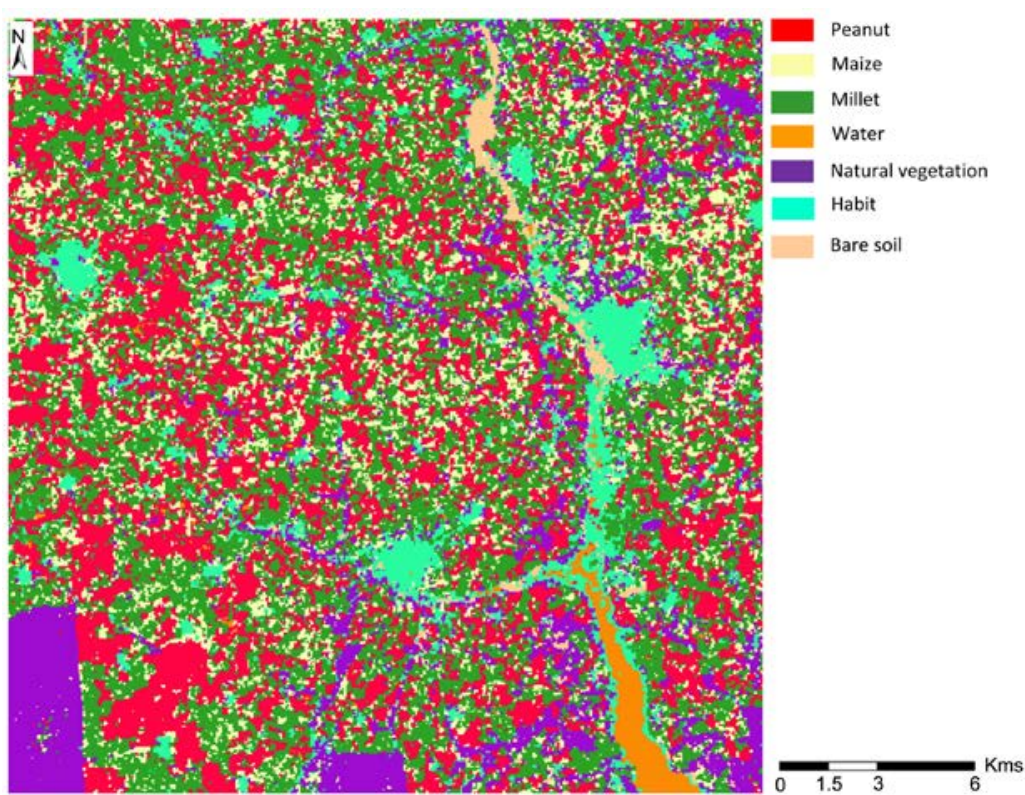

Figure 9. Land cover of the area obtained.

Table 2. Confusion matrix.

\begin{tabular}{cccccccccc}
\hline & Peanut & Maize & Millet & Water & $\begin{array}{c}\text { Natural } \\
\text { vegetatio }\end{array}$ & Habit & Bare soil & Total & Error C \\
\hline Peanut & 9593 & 577 & 142 & 0 & 68 & 0 & 0 & 10,379 & 0.0758 \\
Maize & 366 & 3636 & 1924 & 0 & 19 & 0 & 00 & 5945 & 0.3884 \\
Millet & 301 & 3327 & 7133 & 0 & 68 & 86 & 0 & 10,915 & 0.3465 \\
Water & 30 & 0 & 0 & 5243 & 0 & 0 & 0 & 5273 & 0.0057 \\
Natural & 80 & 227 & 58 & 0 & 7557 & 0 & 0 & 7922 & 0.0461 \\
vegetation & & 154 & 65 & 0 & 0 & 8704 & 0 & 8923 & 0.0245 \\
Habit & 0 & 10 & 0 & 0 & 1 & 161 & 2596 & 2768 & 0.0621 \\
Bare soil & 0 & 10 & & & & & & & \\
Total & 10,369 & 7931 & 9322 & 5243 & 7713 & 8951 & 2596 & 52,125 & \\
Error C & 0.0749 & 0.5415 & 0.2348 & 0.0000 & 0.0202 & 0.0276 & 0.0000 & & 0.1470 \\
\hline
\end{tabular}

Kappa $=0.8251$.

the late harvest of peanut which began in the last 10-day period of October when the millet and maize are already harvested. Thus, during the first $2 / 3$ of October, peanut was still in a phase of intense chlorophyllous activity.

The radar data confirmed the differences noted with the optical data but the time series provides greater precision (14 radar images against only 3 optics). Until day 253 of the year (09 September) radar signals of the three crops remained confused under both $\mathrm{VV}$ and $\mathrm{VH}$ polarizations. However, the $\mathrm{I}_{\mathrm{G}}$ index (amplified ratio VH/VV) showed a slight difference between millet and the two other crops on day 192 and day 204 of year (July 11 and 23). This difference could result from cropping practices where peanut and maize plowing is often much more marked than for millet, as the two polarizations do not have the 
same sensitivities to roughness [31]. Between the day 253 and day 300 of the year (September $9^{\text {th }}$ and October $27^{\text {th }}$ ), the signals of millet and maize were lower than that of peanut under both polarizations. This, because this period corresponded to the harvest of cereal crops (millet and maize), while peanut has not yet completed its phenological cycle. However, there was a reversal of signals beyond October 27 (day 300 of the year) with a sharp drop of peanut signal corresponding to the beginning of its harvest during which all the plant is cut to leave a completely bare soil. During this period, the difference between the peanut and cereal (millet and maize) backscatter coefficient reached $2 \mathrm{~dB}$ in VV and $5 \mathrm{~dB}$ in $\mathrm{VH}$ polarization, indicating the possibility of discriminating this crop at the end of the rainy season.

Combining optical and radar images show strong potential for distinguishing between the three crops with more than $85 \%$ of precision. However, the differentiation of millet and maize remained difficult especially with the radar where the difference in signals rarely exceeds $1 \mathrm{~dB}$ throughout the rainy season. It's only in December that there is a real difference (up to $2 \mathrm{~dB}$ ). Only the $\mathrm{I}_{\mathrm{G}}$ index of 11 July and the NDVI of October 07 discriminated millet and maize but with small differences.

\section{Conclusions}

The paper examined the capacity of satellite data to map crops (peanut, millet and maize) in the Sahelian context where parcels are small (less than 2 hectares).

The purpose of this study is to achieve a multi-temporal and multi-sensor analysis method that allows mapping small crop parcels by combining optical (Sentinel-2) and radar (Sentinel-1) data.

Optical satellite data gives a better result towards the end of rainy season, period during which we note differences between the NDVI of millet and that of peanut

Radar data show, by combining the two bands (VV and VH), differences between crops at the beginning of season. This may relate to differences in agricultural practices. Indeed, peanut and maize are usually sown by plowing, thereby affecting soil roughness which influences the radar signal in VV and VH.

Significant differences in the two polarizations (VV and VH) were noted towards the end of the rainy season (October) due to the fact that the three crops were not harvested at the same period and in the same way.

Combination of optic and radar data made it possible to considerably improve the discrimination of the three crops with a global accuracy of the $82 \%$. However, the capacity of satellite data to discriminate the three crops depends on the period during the growing season.

In order to improve the results once again, mathematical and classification algorithms are being developed.

\section{Acknowledgements}

This work is carried out within the framework of the research project funded by 
Centre dexcellence Africain en Mathématique, Informatique et Technologie de I Information et de la Communication CEA-MITIC of Gaston Berger University of Saint-Louis, Senegal. We warmly thank CEA-MITIC for accepting this work.

\section{Conflicts of Interest}

The authors declare no conflicts of interest regarding the publication of this paper.

\section{References}

[1] CORAF/WECARD (2007) Strategic Plan 2007-2016. CORAF/WECARD, Dakar.

[2] Fritz, S., See, L. and Rembold, F. (2010) Comparison of Global and Regional Land Cover Maps with Statistical Information for the Agricultural Domain in Africa. International Journal of Remote Sensing, 31, 2237-2256.

https://doi.org/10.1080/01431160902946598

[3] Vancutsem, C., Marinho, E., Kayitakire, F., See, L. and Fritz, S. (2012) Harmonizing and Combining Existing Land Cover/Land Use Datasets for Cropland Area Monitoring at the African Continental Scale. Remote Sensing, 5, 19-41.

https://doi.org/10.3390/rs5010019

[4] Delrue, J., Bydekerke, L., Eerens, H., Gilliams, S., Piccard, I. and Swinnen, E. (2013) Crop Mapping in Countries with Small-Scale Farming: A Case Study for West Shewa, Ethiopia. International Journal of Remote Sensing, 34, 2566-2582. https://doi.org/10.1080/01431161.2012.747016

[5] Lambert, M.-J., Waldner and Defourny, P. (2016) Cropland Mapping over Sahelian and Sudanian Agrosystems: A Knowledge-Based Approach Using PROBA-V Time Series at 100-m. Remote Sensing, 8, 232. https://doi.org/10.3390/rs8030232

[6] Shelestov, A., Lavreniuk, M., Kussul, N., Novikov, A. and Skakun, S. (2017) Exploring Google Earth Engine Platform for Big Data Processing: Classification of Multi-Temporal Satellite Imagery for Crop Mapping. Frontiers in Earth Science, 5, 17. https://doi.org/10.3389/feart.2017.00017

[7] Onojeghuo, A.O., Blackburn, G.A., Wang, Q., Atkinson, P.M., Kindred, D. and Miao, Y. (2017) Mapping Paddy Rice Fields by Applying Machine Learning Algorithms to Multi-Temporal Sentinel-1A and Landsat Data. International Journal of Remote Sensing, 39, 1042-1067. https://doi.org/10.1080/01431161.2017.1395969

[8] Bégué, A., Arvor, D., Bellon, B., Betbeder, J., De Abelleyra, D., Ferraz, R., Verón, S., et al. (2018) Remote Sensing and Cropping Practices: A Review. Remote Sensing, 10, 99. https://doi.org/10.3390/rs10010099

[9] Kaboro, S., Niall, P.H. and Yacouba, D. (2018) Assessing Cropland Area in West Africa for Agricultural Yield Analysis. Remote Sensing, 10, 1785.

https://doi.org/10.3390/rs10111785

[10] Bégué, A., Lebourgeois, V., Bappel, E., Todoroff, P., Pellegrino, A., Baillarin, F. and Siegmund, B. (2010) Spatio-Temporal Variability of Sugarcane Fields and Recommendations for Yield Forecast Using NDVI. International Journal of Remote Sensing, 31, 5391-5407. https://doi.org/10.1080/01431160903349057

[11] Rakotoniaina, S., Rakotomandrindra, P., Ranaivoarimanana, S. and Rakotondraompiana, S. (2014) La cartographie et la télédétection comme système d'évaluation des TGRNR. Exemple de site d'application: La commune de Didy, région d'AloatraMangoro, Madagascar. 
[12] Lisboa, I.P., Damian, J.M., Cherubin, M.R., Silva Barros, P.P., Fiorio, P.R., Cerri, C.C. and Cerri, C.E.P. (2018) Prediction of Sugarcane Yield Based on NDVI and Concentration of Leaf-Tissue Nutrients in Fields Managed with Straw Removal. Agronomy, 8, 196. https://doi.org/10.3390/agronomy8090196

[13] Knauer, K., Gessner, U., Dech, S. and Kuenzer, C. (2014) Remote Sensing of Vegetation Dynamics in West Africa. International Journal of Remote Sensing, 35, 37-41. https://doi.org/10.1080/01431161.2014.954062

[14] Nagai, S., Nasahara, K.N., Muraoka, H., Akiyama, T. and Tsuchida, S. (2010) Field Experiments to Test the Use of the Normalized-Difference Vegetation Index for Phenology Detection. Agricultural and Forest Meteorology, 150, 152-160. https://doi.org/10.1016/j.agrformet.2009.09.010

[15] Wu, C., Peng, D., Soudani, K., Siebicke, L., Gough, C.M., Arain, M.A., Bohrer, G., Lafleur, P.M., Peichl, M., Gonsamo, A., et al. (2017) Land Surface Phenology Derived from Normalized Difference Vegetation Index (NDVI) at Global Fluxnet Sites. Agricultural and Forest Meteorology, 233, 171-182. https://doi.org/10.1016/j.agrformet.2016.11.193

[16] Karkauskaite, P., Tagesson, T. and Rasmus Fensholt, R. (2017) Evaluation of the Plant Phenology Index (PPI), NDVI and EVI for Start-of-Season Trend Analysis of the Northern Hemisphere Boreal Zone. Remote Sensing, 9, 485. https://doi.org/10.3390/rs9050485

[17] Hmimina, G., Dufrene, E., Pontailler, J.Y., Delpierre, N., Aubinet, M., Caquet, B., de Grandcourt, A., Burban, B., Flechard, C., Granier, A., et al. (2013) Evaluation of the Potential of MODIS Satellite Data to Predict Vegetation Phenology in Different Biomes: An Investigation Using Ground-Based NDVI Measurements. Remote Sensing of Environment, 132, 145-158. https://doi.org/10.1016/j.rse.2013.01.010

[18] Eastman, J.R., Sangermano, F., Machado, E.A., Rogan, J. and Anyamba, A. (2013) Global Trends in Seasonality of Normalized Difference Vegetation Index (NDVI), 1982-2011. Remote Sensing, 5, 4799-4818. https://doi.org/10.3390/rs5104799

[19] Diouf, A.A., Hiernaux, P., Brandt, M., Faye, G., Djaby, B., Diop, M.B., Ndione, J.A. and Tychon, B. (2016) Do Agrometeorological Data Improve Optical Satellite-Based Estimations of Herbaceous Yield in Sahelian Semi-Arid Ecosystems? Remote Sensing, 8, 668. http://www.mdpi.com/journal/remotesensing https://doi.org/10.3390/rs8080668

[20] Zhang, L., Qiao, N., Baig, M.H.A., Huang, C., Lv, X., Sun, X. and Zhang, Z. (2019) Monitoring Vegetation Dynamics Using the Universal Normalized Vegetation Index (UNVI): An Optimized Vegetation Index-VIUPD. Remote Sensing Letters, 10, 629-638. https://doi.org/10.1080/2150704X.2019.1597298

[21] Gholizadeh, A. and Kopackova, V. (2019) Detecting Vegetation Stress as a Soil Contamination Proxy: A Review of Optical Proximal and Remote Sensing Techniques. International Journal of Environmental Science and Technology, 16, 2511-2524. https://doi.org/10.1007/s13762-019-02310-w

[22] Faye, G., Frison, P.L., Diouf, A.A., Wade, S., Kane, C.A., Fussi, F., Jarlan, L., Niang, F.K.N., Ndione, J.A. and Mougin, E. (2017) Soil Estimation in the Ferlo Region (Senegal) Using Radar ENVISAT/ASAR and Optical SPOT/VEGETATION Data. The Egyptian Journal of Remote Sensing and Space Science, 21, S13-S22. https://doi.org/10.1016/j.ejrs.2017.11.005

[23] Brink, M. and Belay, G.M. (2006) Ressources végétales de l'Afrique tropicale 1. Céréales et légumes secs. Foundation PROTA/Backhuys Publishers/CTA, Pays-Bas, Wageningen. 
[24] Stomal-Weigel B. (1988) L'évolution récente et comparée des systèmes de production serer et wolof dans deux villages du vieux Bassin arachidier (Sénégal). Cahier des Sciences Humaines, 24, 17-33.

[25] Baup, F. (2007) Apport des données Envisat/Asar pour le suivi des surfaces continentales: Applicationà la zone sahélienne. Thèse de l'Université Paul Sabatier de Toulouse, $198 \mathrm{p}$.

[26] Zine, S., Jarlan, L., Frison, P.L., Mougin, E., Hiernaux, P. and Rudant, J.P. (2005) Land Surface Parameter with ERS Scatterometer Data over the Sahel: A Comparison between Agro-Pastoral and Pastoral Areas. Remote Sensing of Environment, 693, 438-452. https://doi.org/10.1016/j.rse.2005.04.012

[27] Tamim, A. (2015) Segmentation et classification des images satellitaires: Application à la détection des zones d'upwelling côtier marocain et mise en place d'un logiciel de suivi spatiotemporel. Traitement du signal et de l'image [eess.SP]. Université Mohammed V Faculté Des Sciences Rabat 2015.

[28] Faye, G., Frison, P.L., Wade, S., Ndione, J.A., Beye, A.C. and Rudant, J.P. (2011) Etude de la saisonnalité des mesures des diffusiomètres SCAT: Apport au suivi de la végétation au Sahel, cas du Ferlo au Sénégal. Télédétection, 10, 23-31.

[29] Fatras, C., Frappart, F., Mougin, E., Grippa, M. and Hiernaux, P. (2012) Estimating Surface Soil Moisture over Sahel Using ENVISAT Radar Altimetry. Remote Sensing of Environment, 123, 496-507. https://doi.org/10.1016/j.rse.2012.04.013

[30] Blackwell, W., Elachi, C., Fung, A., Ruf, C., Sarabandi, K., Zebker, H. and Zyl, J. (2014) Microwave Radar and Radiometric Remote Sensing. University of Michigan Press, Ann Arbor.

[31] Grippa, M. and Woodhouse, I.H. (2002) Validation of Surface Scattering Models across Large Footprints for Global Scatterometer Applications. IEEE Transactions on Geoscience and Remote Sensing, 40, 2229-2233.

https://doi.org/10.1109/TGRS.2002.804727 